\title{
Reimplantation: Clinical Implications and Outcome of Dry Storage of Avulsed Teeth
}

\author{
Anshu Singla ${ }^{1}$, Shalini Garg ${ }^{2}$, Abhishek Dhindsa ${ }^{3}$, Sanjeev Jindal ${ }^{4}$ \\ ${ }^{1}$ Senior Lecturer, Department of Pedodontics \& Preventive Dentistry, Bhojia Dental College \& Hospital, Vill. Bhud, Baddi, \\ Tehsil Nalagarh, Himachal Pradesh. \\ ${ }^{2}$ Professor and Head Department, Department of Pedodontics \& Preventive Dentistry, M.M. College of Dental Sciences \& Re- \\ search, Mullana, Ambala, Haryana, India. \\ ${ }^{3}$ Reader, Department of Pedodontics \& Preventive Dentistry, M.M. College of Dental Sciences \& Research, Mullana, Ambala, \\ Haryana, India. \\ ${ }^{4}$ Senior Lecturer, Department of Oral Medicine \& Radiology, Bhojia Dental College \& Hospital, Vill. Bhud, Baddi, Tehsil Nala- \\ garh, Himachal Pradesh.
}

Correspondence:

Dr. Anshu Singla,

Department of Pedodontics \& Preventive Dentistry,

Bhojia Dental College \& Hospital

Vill. Bhud, Baddi, Tehsil Nalagarh,

Himachal Pradesh - 173205, INDIA

E-mail;saj2908@yahoo.com

\begin{abstract}
Reimplantation refers to the insertion and temporary fixation of completely or partially avulsed teeth that have resulted from traumatic injury. Reimplantation of an avulsed tooth depends on certain clinical conditions like physiological status of periodontal ligament (PDL), the stage of root development and the length of extra oral time. Depending on the patient's age, retention of the permanent incisor can maintain the aesthetic appearance, occlusal function and alveolar ridge height. Though the risk of progressive replacement resorption and subsequent tooth loss is high after a long dry storage, reimplantation makes a provision for an aesthetically acceptable permanent prosthesis at a later age. This article presents management of two cases with avulsed permanent incisors that were stored in dry conditions for seven hours and three days respectively.
\end{abstract}

Key words: Delayed reimplantation, tooth avulsion, dry storage. 


\section{Introduction}

Avulsion of teeth results from traumatic injuries in the oro-facial region. Following the World Health Organization's classification system later modified by Andreasen, avulsion is classified as an injury of periodontal tissues, as well as extrusive, lateral, or intrusive luxation (1). As a treatment option, reimplantation restores occlusal function and esthetics shortly after injury. In reimplantation complete reestablishment of vitality of periodontal fibers is the prime objective. The percentage of success of tooth reimplantation has been observed to be low, ranging from 4 to $50 \%$ (2). However, it should be emphasized that the consideration of success of tooth reimplantation should take into account the clinical needs and patient expectations. The period of permanence of the tooth in the dental arch may be enough to meet some of the needs, such as prevention of atrophy of the alveolar ridge, allows the patient to better assimilate the tooth loss, and even delay the need for prosthesis (3). The success of tooth reimplantation depends on the maintenance of vitality of the periodontal ligament, allowing its remnants adhered to the avulsed tooth to survive and recover their function (4). Resorption is the main cause of failure of reimplantations, and the prognosis of a reimplanted tooth is related to the type of resorption that may ultimately lead to complete destruction of the root (5). Degeneration of the periodontal ligament depends on several factors, such as trauma, management of the root, extra-alveolar period and storage medium (6-8). The need to perform endodontic treatment has been demonstrated by several authors, as the pulp tissue may present necrosis and its toxins may reach the periodontal ligament through the dentinal tubules or root canal, definitely contributing to an increase in the resorption process (9-10).

Nevertheless, if managed appropriately, avulsed teeth with viable periodontal ligament when reimplanted can remain functional for some years. This article describes the management of two children with an avulsed maxillary permanent incisor that had been kept in a non-physiological media for 7 hours and 3 days respectively.

\section{Case Reports}

Case report 1

A 14-year-old male reported to the Department of Pedodontics and Preventive Dentistry at M.M.College of Dental Sciences and research, Mullana for treatment of avulsed teeth in an afternoon session. He had trauma 7 hours earlier and spat out his upper front teeth. On intraoral examination, it was found that his maxillary right and left central incisors and maxillary right lateral incisor had been avulsed (Fig. 1). The avulsed teeth had been kept dry in a paper handkerchief after the injury. The patient's medical history was unremarkable. All of the adjacent teeth showed positive response to the vita-

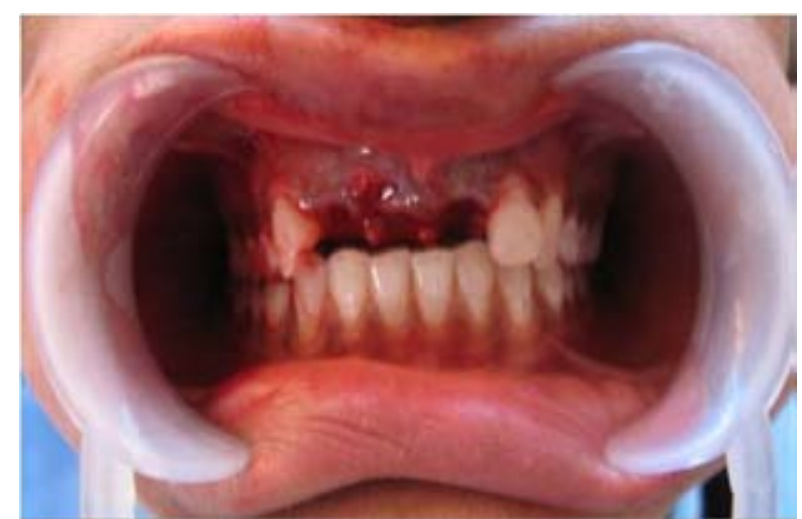

Fig 1. Showing avulsed maxillary right and left central incisor and maxillary right lateral incisor teeth

lity test. On radiological examination periapical radiography (Fig. 2) revealed no other hard-tissue injury and panoramic radiograph confirmed no maxillary or mandibular fractures. Examination of the avulsed teeth revealed that the roots had closed apices and tooth crowns were intact.

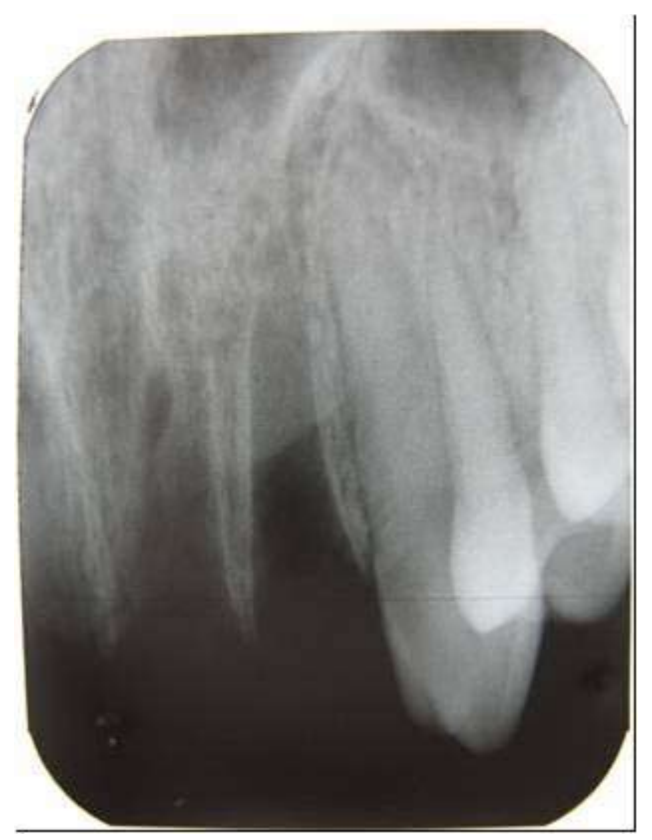

Fig 2. Intraoral periapical radiograph revealing empty sockets with no other hard-tissue injury

Reimplantation of the teeth was planned to retain the teeth in the mouth for as long a period as possible because of the patient's age, although the teeth were stored in extremely unfavourable conditions. As this case was of delayed reimplantation, endodontic treatment was started before reimplantation. Cleaning of the tooth surfaces was carried out with saline and betadine. Root canal enlargement and cleaning was performed. The root canals were then dried with sterile paper points and filled with gutta percha points and sealer.

Under local anaesthesia, the sockets were gently curetted to remove any coagulum, granulation tissue and patholo- 
gic tissue and irrigated with physiologic saline solution. Teeth were then soaked in $2.4 \%$ sodium fluoride solution and reimplanted into their respective sockets. Once the teeth were properly seated, they were checked for alignment or occlusion and were splinted to the adjacent teeth with a $0.5 \mathrm{~mm}$ stainless steel round wire and acid-etch composite. Maxillary occlusal radiograph was obtained to confirm proper positioning of the reimplanted teeth. Oral hygiene instructions were given and chlorhexidine mouthwash was recommended.

Patient did not show any clinical symptoms like mobility, periodontal pockets etc. and any type of root resorption after 6 weeks of follow-up. The splinting was then removed. The patient was on regular follow-up thereafter for 2 years. During this follow-up period, the patient was asymptomatic and pleased with the conservative treatment (Fig. 3a-3b)

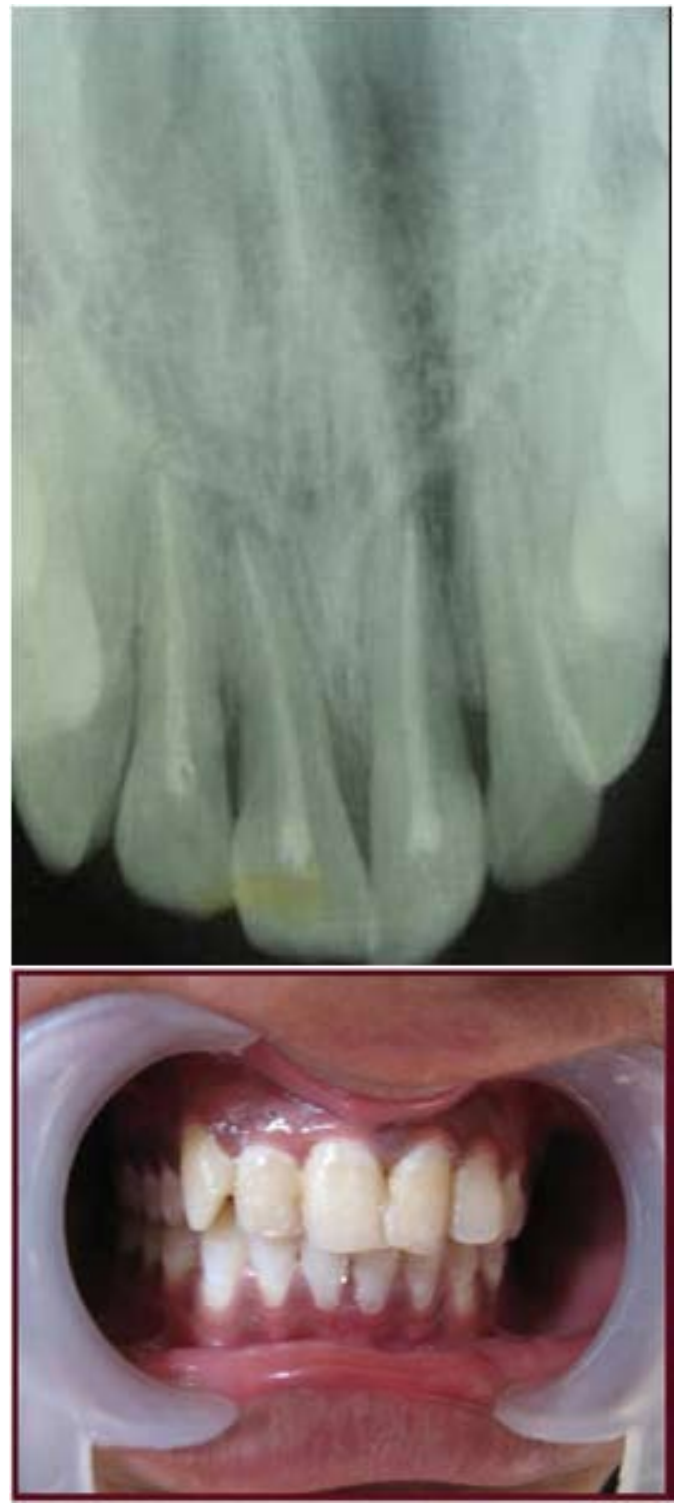

Fig 3a. Maxillary occlusal radiograph after 2 years Fig 3b. Clinical picture after splinting removal

\section{Case report 2}

An 11-year-old female reported to the Department of Pedodontics and Preventive Dentistry at M.M.College of Dental Sciences and research, Mullana with complete avulsion of her maxillary right central and left lateral incisors, three days after trauma. Her left lateral incisor was intact, but the right central incisor had an uncomplicated enamel fracture (Fig. 4). The avulsed teeth had been left dry in a piece of cloth after the injury.

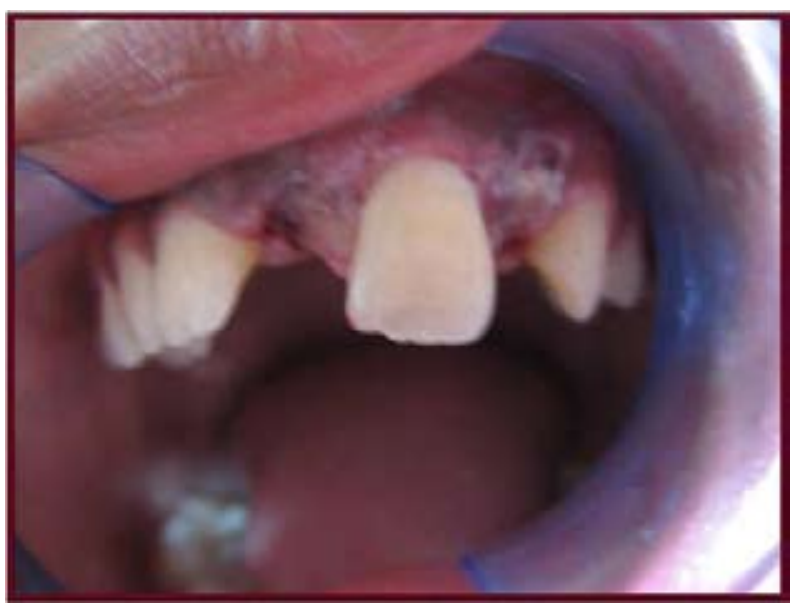

Fig 4. Showing avulsed maxillary right central and left lateral incisor

There was no significant medical and dental history. On radiological examination periapical radiography revealed no other hard-tissue injury (Fig. 5). Reimplantation of the teeth was planned to retain the teeth in the oral cavity for as long a period as possible. As this was also a case of delayed reimplantation, endodontic treatment was carried out prior to reimplantation. Cleaning of the tooth surfaces was carried out with saline and betadine. Conventional enlargement and cleaning of the root canals were performed. The root canals were then dried with sterile paper points and filled with gutta percha points and sealer.

Coronal root canal openings were sealed with glass ionomer cement. Then, about $2 \mathrm{~mm}$ of apices were resected to ensure easily seating of roots into sockets. The apical preparations were dried with sterile paper points and obturated with amalgam by means of amalgam carrier and then compacted into place. The teeth were then irrigated with saline and betadine and placed in $2.4 \%$ solution of sodium fluoride for 20 minutes. Then, the incisors were reimplanted into their respective sockets and checked for alignment or occlusion and were splinted to the adjacent teeth with fibre splint and composite. Periapical and occlusal radiographs were obtained to confirm proper positioning of the reimplanted teeth. Patient was placed on systemic coverage and discharged with oral hygiene instructions.

Patient was recalled at 15 days interval for 6 weeks after which splinting was removed. The patient was asympto- 


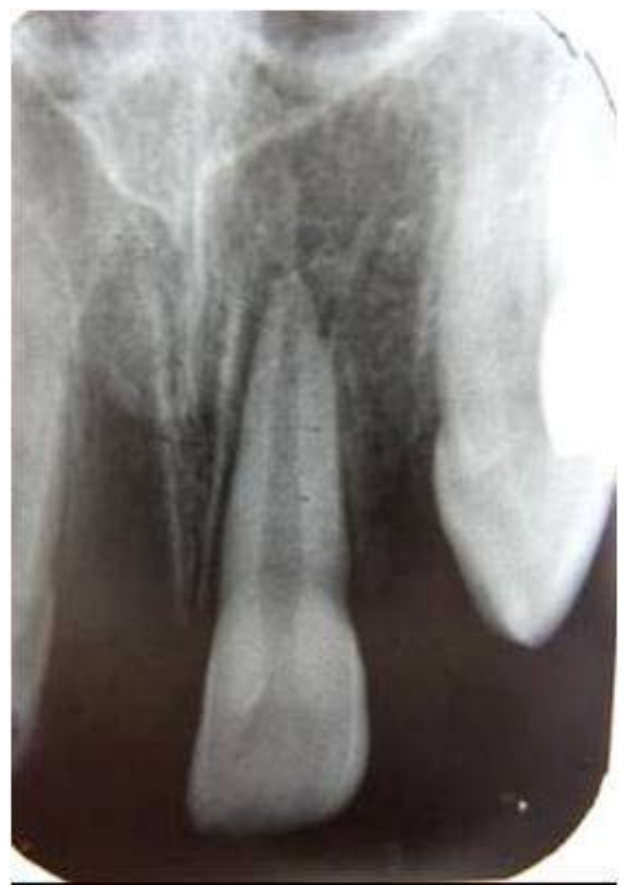

Fig 5. Inraoral periapical revealing empty sockets with no other hard-tissue injury

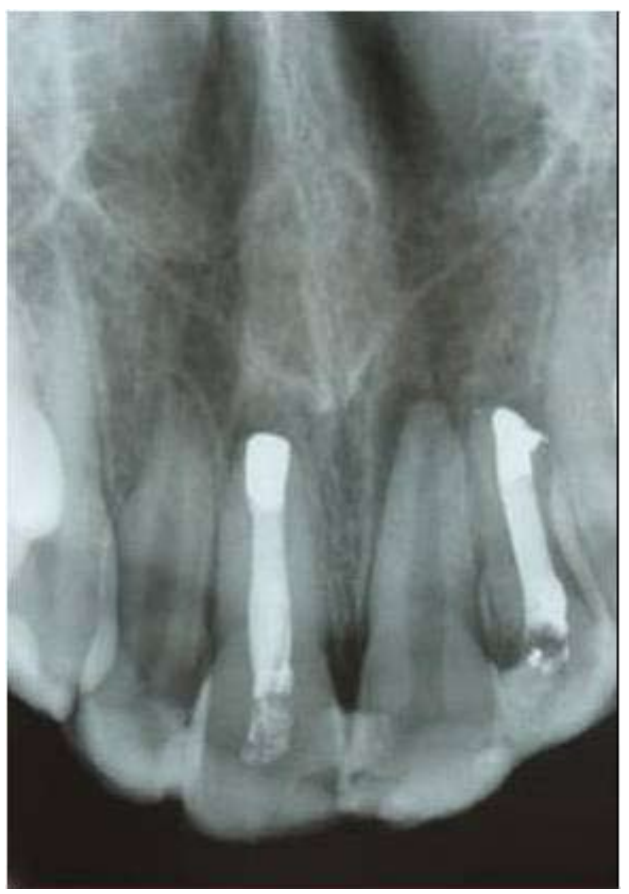

Fig 6. Maxillary occlusal radiograph after 1 year showing no resorption

matic with no unfavourable clinical and radiographical changes after one year of follow-up (Fig. 6).

\section{Discussion}

Tooth avulsion is a serious assault on the gingiva, periodontal ligament and pulp. Young permanent tooth loss leads to severe arrest of alveolar bone formation in a growing child. Alveolar ridge would be narrow and difficult to restore in future with either a bridge or implant. Most conservative approach for managing the avulsed incisors is to reimplant them as soon as possible. In clinical studies, teeth replanted within 5 minutes after avulsion had the best prognosis and the chance of pulpal and periodontal healing was inversely related to the stage of root development and the period of dry storage (10). But immediate reimplantation is not always possible because of various unavoidable problems.

In the cases presented here, avulsed teeth had been stored in a non-physiological media for prolonged periods by patients. It was anticipated that periodontal ligament was irreversibly damaged so ankylosis will result. Reimplantation of the avulsed teeth was decided in growing children inspite of extremely unfavorable conditions like dry storage and prolonged extraoral time. The treatment objective was to retain the avulsed incisors in best esthetic and occlusal form in oral cavity. Future aim was to achieve periodontal and osseous healing with replacement root resorption. This minimally intervention though interim surgical procedure, maintained alveolar bone dimensions and provided time for further invasive permanent tooth rehabilitation procedures, once the growth is complete. The avulsed teeth were splinted to the adjacent teeth with rigid wire for 6 weeks to facilitate rapid, ankylosis $(1,11)$. Gingival level simulated a normal relationship of maxillary anterior teeth. This mechanism of replacement resorption of a tooth is remodelling with osseous tissue and the speed of replacement resorption correlates to the remodelling speed of bone (fast in young people and slow in adults). Ebeleseder et al. suggested that reimplanting avulsed teeth should be considered as a temporary solution in children and adolescents (12). In these patients, the greatest benefit of successful reimplanation of an avulsed tooth is preservation of alveolar bone. Even if the reimplanted tooth must be extracted later, the improved alveolar development will provide better options for restoration of the site later. We could successfully achieve objectives like acceptable esthetic appearance and occlusal function, prevention of root resorption and favorable healing for better permanent treatment considerations in later life. Patients were asymptomatic and fully satisfied with the treatment with a follow up of 24 months and 12 months. This procedure gave invaluable and timely contribution in their normal and physiological growth.

\section{References}

1. Lin S, Zuckerman O, Fuss Z, Ashkenazi M; American Association of Endodontists; International Association of Dental Traumatology; Royal College of Surgeons of England. New emphasis in the treatment of dental trauma. Dent Traumatol. 2007;23:297-303.

2. Andreasen JO, Borum MK, Jacobsen HL, Andreasen FM. Replantation of 400 avulsed permanent incisors. 4. Factors related to periodontal ligament healing. Endod Dent Traumatol. 1995;11:76-89.

3. Duggal MS, Ogden AR. Combined orthodontic and restorative ma- 
nagement of oligodontia. Dent Update. 1990;17:210-2.

4. Andreasen JO. A time-related study of periodontal healing and root resorption activity after replantation of mature permanent incisors in monkeys. Swed Dent J. 1980;4:101-10.

5. Andreasen JO. Effect of extra-alveolar period and storage media upon periodontal and pulpal healing after replantation of mature permanent incisors in monkeys. Int J Oral Surg. 1981;10:43-53.

6. Askenazi M, Marouni M, Sarnat $H$. In vitro viability, mitogenicity and clonogenic capacites of periodontal ligament fibroblasts after storage in four media supplemented with growth factors. Dent Traumatol. 2001;17:27-35

7. Andreasen JO. The effect of pulp extirpation or root canal treatment on periodontal healing after replantation of permanent incisors in monkeys. J Endod. 1981;7:245-52.

8. Massarstrom LE, Blomlof LB, Feiglin B, Lindskog SF. Effect of calcium hydroxide treatment on periodontal repair and root resorption. Endod Dent Traumatol. 1986;2:184-9.

9. Trope M, Moshonov J, Nissan R, Buxt P, Yesilsoy C. Short vs. long-term calcium hydroxide treatment of established inflammatory root resorption in replanted dog teeth. Endod Dent Traumatol. 1995; 11:124-8.

10. Barrett EJ, Kenny DJ. Avulsed permanent teeth: a review of the literature and treatment guidelines. Endod Dent Traumatol. 1997;13:15363.

11. Duggal MS, Toumba KJ, Russell JL, Paterson SA. Replantation of avulsed permanent teeth with avital periodontal ligaments: case report. Endod Dent Traumatol. 1994;10:282-5.

12. Ebeleseder KA, Friehs S, Ruda C, Pertl C, Glockner K, Hulla H. A study of replanted permanent teeth in different age groups. Endod Dent Traumatol. 1998;14:274-8. 